\title{
SOEP
}

SOEPpapers

SOEPpapers
on Multidisciplinary Panel Data Research

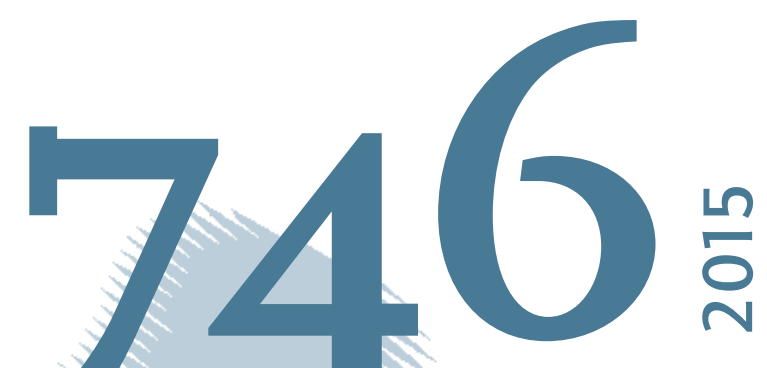

$\stackrel{n}{\text { 은 }}$

$\mathbb{2}$

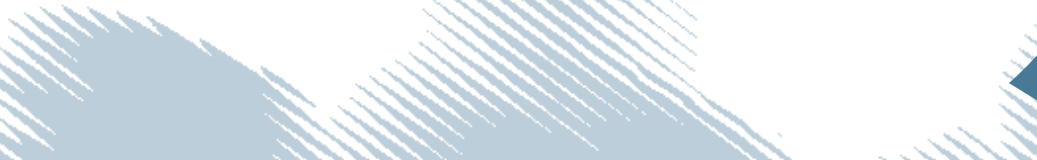

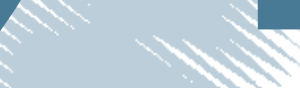

nos?

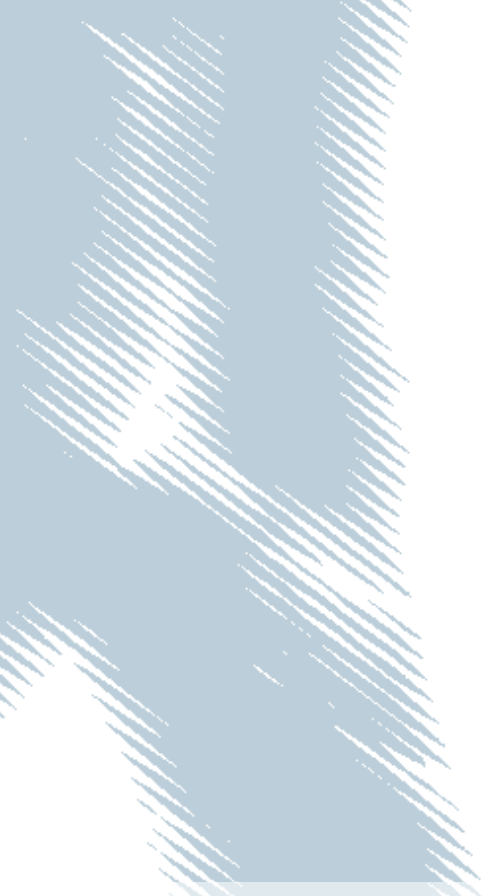

\section{Dynamic Properties of Energy Affordability Measures}


This series presents research findings based either directly on data from the German SocioEconomic Panel study (SOEP) or using SOEP data as part of an internationally comparable data set (e.g. CNEF, ECHP, LIS, LWS, CHER/PACO). SOEP is a truly multidisciplinary household panel study covering a wide range of social and behavioral sciences: economics, sociology, psychology, survey methodology, econometrics and applied statistics, educational science, political science, public health, behavioral genetics, demography, geography, and sport science.

The decision to publish a submission in SOEPpapers is made by a board of editors chosen by the DIW Berlin to represent the wide range of disciplines covered by SOEP. There is no external referee process and papers are either accepted or rejected without revision. Papers appear in this series as works in progress and may also appear elsewhere. They often represent preliminary studies and are circulated to encourage discussion. Citation of such a paper should account for its provisional character. A revised version may be requested from the author directly.

Any opinions expressed in this series are those of the author(s) and not those of DIW Berlin. Research disseminated by DIW Berlin may include views on public policy issues, but the institute itself takes no institutional policy positions.

The SOEPpapers are available at http://www.diw.de/soeppapers

\section{Editors:}

Jan Goebel (Spatial Economics)

Martin Kroh (Political Science, Survey Methodology)

Carsten Schröder (Public Economics)

Jürgen Schupp (Sociology)

Conchita D'Ambrosio (Public Economics)

Denis Gerstorf (Psychology, DIW Research Director)

Elke Holst (Gender Studies, DIW Research Director)

Frauke Kreuter (Survey Methodology, DIW Research Fellow)

Frieder R. Lang (Psychology, DIW Research Fellow)

Jörg-Peter Schräpler (Survey Methodology, DIW Research Fellow)

Thomas Siedler (Empirical Economics)

C. Katharina Spieß (Education and Family Economics)

Gert G. Wagner (Social Sciences)

ISSN: 1864-6689 (online)

German Socio-Economic Panel Study (SOEP)

DIW Berlin

Mohrenstrasse 58

10117 Berlin, Germany

Contact: Uta Rahmann | soeppapers@diw.de 


\title{
Dynamic Properties of Energy Affordability Measures
}

\author{
Peter Heindl* \\ Department of Environmental and Resource Economics \\ Centre for European Economic Research, Mannheim (Germany) \\ and \\ Rudolf Schüssler** \\ Department of Philosophy \\ University of Bayreuth (Germany)
}

\begin{abstract}
- Abstract -
Measures of affordability are applied in practice, e.g., to assess the affordability of energy services, water or housing. They can be interpreted as measures of deprivation in a specific domain of consumption. The large body of literature on affordability measure has little overlap with the existing literature on poverty measurement. A comprehensive assessment of the response of affordability measures as a result of changes in the distribution of income or expenditure is missing. This paper aims to fill this gap by providing a conceptual discussion on the 'dynamics' of energy affordability measures. Several types of measures are examined in a microsimulation framework to assess their dynamic properties. Our results indicate that some measures exhibit odd dynamic behavior. This includes measures used in practice, such as the low income/high cost measure and the double median of expenditure share indicator. Odd dynamic behavior is attributed to definitions made with respect to higher moments of the expenditure distribution. Definitions that rely on a percentage share of expenditure relative to income or an absolute or relative income poverty line fare well from a dynamic perspective.
\end{abstract}

Keywords: affordability measure; energy poverty; fuel poverty

JEL-Classification: I32; D63; Q48

\section{Acknowledgements:}

* Heindl: Centre for European Economic Research (ZEW), L7 1, 68161 Mannheim, Germany, mail: heindl@zew.de.

** Schüssler: University of Bayreuth, Dept. of Philosophy, Universitätsstrasse 30, 95440 Bayreuth, Germany, mail: rudolf.schuessler@uni-bayreuth.de.

We are grateful for funding by the German Ministry of Education and Research under grant agreement 01UN1204A and 01UN1204E 'Sozialpolitische Konsequenzen der Energiewende in Deutschland (SOKO Energiewende)'. Such support does not imply agreement with the views expressed in this paper. Thanks also to Philipp Kanschik for helpful comments. 


\section{Introduction}

Measures of affordability are applied in practice and discussed as indicators for deprivation in different domains of consumption. Examples include the assessment of 'fuel poverty' in the United Kingdom (UK) (Boardman, 2012; Liddell et al., 2012), affordability of water (GarcíaValiñas et al., 2010; Gawel et al., 2013), and housing (Bourassa, 1996; Hancock, 1993). Affordability measures are a distinct form of poverty measure that focus on a specific domain in consumption, mostly the consumption of necessities. Many affordability measures are defined on the basis of disposable household income and expenditure and thereby assume the notion of a bivariate poverty measure. The measures often allow the assessment of a 'poverty gap’ (or a weighted poverty gap) and are decomposable based on methods such as the one proposed by Foster, Greer and Thorbecke (1984).

The role of affordability measures in poverty research and their practical use for policymaking is disputed. The practice of assessing fuel poverty in the UK based on affordability measures is criticized for lacking scientific foundation (Healy, 2004), and the existing literature on the issue seems to have little overlap with the general literature on poverty. Despite this criticism, poverty in certain domains of consumption (e.g. energy and housing) has caught the attention of policymakers and the general public. The reasons for this trend are the persistent and partly growing inequality in Europe and beyond (OECD, 2011) or the pronounced (partly temporary) increases in prices for certain goods. While affordability measures are not the only way to assess deprivation in a specific domain of consumption, they represent a (seemingly) transparent and straightforward way to inform about the problem.

Naturally, any definition of affordability should rest upon a rigorous empirical assessment of deprivation in the relevant domains. Well established methods for such an assessment exist (Halleröd, 2006). Given a consensus on which aspects of deprivation in consumption need to be represented, it should be possible to define a meaningful poverty line based on a proper empirical foundation. Most of the literature on fuel poverty or energy poverty in developed countries focuses precisely on this 'static' aspect of affordability, raising the question of how to define deprivation in energy consumption.

The surprisingly large body of literature on the issue neglects one important aspect: the question of how affordability measures respond to changes in underlying variables, such as income or expenditure. The 'dynamic perspective' of poverty is well developed for univariate aggregated poverty measures (Kakwani, 1980; Sen, 1976; Zheng, 1997). However, the 
relevant axioms cannot be directly adapted to affordability measures due to the measures' bivariate nature. It is nevertheless necessary to translate the spirit if not the letter of the axioms of poverty measurement to those of affordability measures to assess their fundamental dynamic properties. In the absence of reasonable dynamic properties, affordability measures would be of little use, whether in the domain of energy consumption or in any other domain.

The aim of this paper is to establish certain conditions to emulate the role of axioms of aggregated poverty measures for affordability measures. Section 2 presents a brief literature review with a strong focus on the discussion on fuel poverty or energy poverty in developed countries since affordability measures are applied to these domains in practice. The next section discusses the relevant normative requirements in a dynamic perspective. Against the backdrop of well-established axioms in univariate aggregate poverty measurement, two propositions are made of how affordability measures should behave in the dynamic perspective. The proposed requirements are tested with a simulation using household data on income and energy expenditure from Germany under consideration of several scenarios and different affordability measures. The two scenarios that are of primary interest examine the cases of a) an increase in expenditure for energy services with implicit ex-post redistribution, and b) increasing income inequality in society. Our results show that some affordability measures (including some that are applied in practice) have counter-intuitive dynamic properties.

\section{Methods}

\subsection{Literature on Energy and Fuel Poverty Measures}

The literature on fuel poverty or energy poverty pivots around two branches of measurement techniques. Consensual measures take a number of variables related to household energy efficiency and energy affordability into account to derive a measure of energy-related deprivation. This approach was first applied by Healy (2004). A more recent pan-European study using consensual measures was presented by Snell and Thomson (2013). Consensual measures depict energy poverty as an interplay between low income and poor residential energy efficiency. That is, consensual measures take aspects of affordability into account, such as the ability to keep the home adequately warm or to make ends meet, along with aspects of energy efficiency, such as leaking roofs or damp walls. This effectively is a combination of both subjective (e.g. ability to keep the home warm) and objective (e.g. leaking roof or damp walls) indicators of energy-related deprivation. 
The second family of measures are affordability measures. These focus on expenditure on energy services and disposable household income. An abundance of various definitions of affordability measures exist. The most well-known energy affordability measure is probably Brenda Boardman's Ten Percent Rule (TPR) (1991). The TPR was long used as the official measure of fuel poverty in the UK (Department of Energy and Climate Change, 2013), and similar measures are used to assess affordability of water (Gawel et al., 2013). The TPR defines a household as fuel poor if it needs to spend ten percent or more of its disposable income on all energy services. The TPR is criticized for lacking scientific foundation and international comparability (Healy, 2004, p. 35), and several alternatives to measure energy poverty have been suggested. Boardman's TPR approximated two-times median expenditure in earlier work by Isherwood and Hancock (1979). Further definitions of energy poverty based on median expenditure are discussed in the literature (Liddell et al., 2012, p. 27-29). Moore (2012), for example, compares the incidence of fuel poverty in the UK over time, inter alia by using a two times median expenditure share indicator (2M). Households are defined as energy poor by $2 \mathrm{M}$ if the expenditure share on all energy services exceeds twice the median expenditure share of the overall population.

In a report commissioned in the UK by the Department of Energy and Climate Change, John Hills presented the Low Income/High Cost indicator (LIHC) as an alternative to the TPR. The LIHC defines a household as energy poor if its expenditure on all energy services is above the median expenditure of all households and when the household falls below the official income poverty line after all expenditure on energy services (Hills, 2012, 2011). As proposed in Moore (2012), definitions of energy poverty could also be based on a Minimum Income Standard (MIS). A household is defined as energy poor if disposable income after expenditure on all energy services falls below the minimum income standard. Minimum income standards or budget standards exist e.g. in Australia (Saunders, 2004, 1999) and have also been put forward for the UK (Bradshaw et al., 2008). In Germany, basic income under the social security scheme (SGBII rates) is determined by a minimum income standard that reflects the average expenditure on several groups of goods of low-income households.

To the best of our knowledge, no contribution has to date been made to the literature on the dynamic properties of affordability measures. Moore (2012) briefly discusses the issue by comparing TPR and 2M in the context of fuel poverty in the UK. He concludes that "the current $10 \%$ of income definition can also exaggerate the impact of fuel prices. [...]" (Moore, 2012, p. 22). Moore's statement of the exaggerated impact of price changes under TPR is 
derived from a comparison to $2 \mathrm{M}$. However, as it is unclear whether $2 \mathrm{M}$ has desirable dynamic properties, Moore’s argument is weak.

There are well established axioms for (dynamic) measurement of income poverty. Seminal contributions have been made by Sen (1976) and Kakwani (1980). Foster et al. (1984) have made an important contribution with respect to techniques for poverty measurement. A comprehensive comparison of existing (income) poverty measures was presented by Zheng (1997). While affordability measures are usually dependent on two variables, namely disposable income and expenditure on a good or a group of goods, standard poverty measures are only dependent on income. Consequently, the widely accepted core axioms on (income) poverty measurement cannot necessarily be generalized to cover those of affordability measures or measures of energy poverty. Yet at least the considerations underlying poverty axioms can be transferred to the case of affordability measures.

\subsection{Dynamic Properties of Affordability Measures}

This paper examines how affordability measures behave under a variation of key parameters, such as income and expenditure. We focus on the case of energy poverty as a large body of literature referring to affordability already exists and the issue has been gaining attention across Europe. However, before proceeding to the simulation of these issues, some guiding theoretical considerations seem in order. A few well-known indicators (or their standard interpretations) stand in a problematic relationship with the conditions postulated as axioms in the literature on poverty measurement, or they violate requirements that appear as plausible as these axioms. It stands to reason that measures of poverty should be plausible under a variation of income or expenditure in a society, and the same holds true for indicators of energy poverty. Indicators that fail this test should be discarded or modified. Dynamic simulations will help identify respective shortcomings and determine whether modified indicators perform better. It is undisputable that poverty measures and energy poverty indicators should also satisfy certain ethical requirements, which can be derived from theories of distributive (or social) justice. ${ }^{1}$ However, we assume that ethical requirements might be more controversial than plausibility checks, and should be considered a second filter for poverty indicators after basic plausibility requirements have been met. We will therefore focus on the latter here.

\footnotetext{
${ }^{1}$ See, e.g., Blackorby and Donaldson (1980), Papadopoulos and Tsakoglou (2008), Pogge (2007).
} 
Which indicators will be discussed? Energy poverty is commonly understood as the nonavailability of adequate energy services, either due to a lack of access to energy or its nonaffordability. In developed OECD economies, which we focus on in this paper, physical nonavailability is rare, except as result of an inability to pay. Hence, economic reasons for energy poverty stand at the forefront here. Three concepts for the construction of affordability indicators with respect to energy services emerge from the literature. The first concept focuses on an appropriate cost share of energy services in the consumption budget of a household, or more simply put, its income. The second one looks at the appropriateness of energy expenditure as such. In the last concept, energy poverty, or non-affordability, is understood as a situation in which a household is pushed into income poverty because of its energy expenditure. Since these approaches differ conceptually, they can be represented by an ‘indicator triangle’ (see Figure 1).

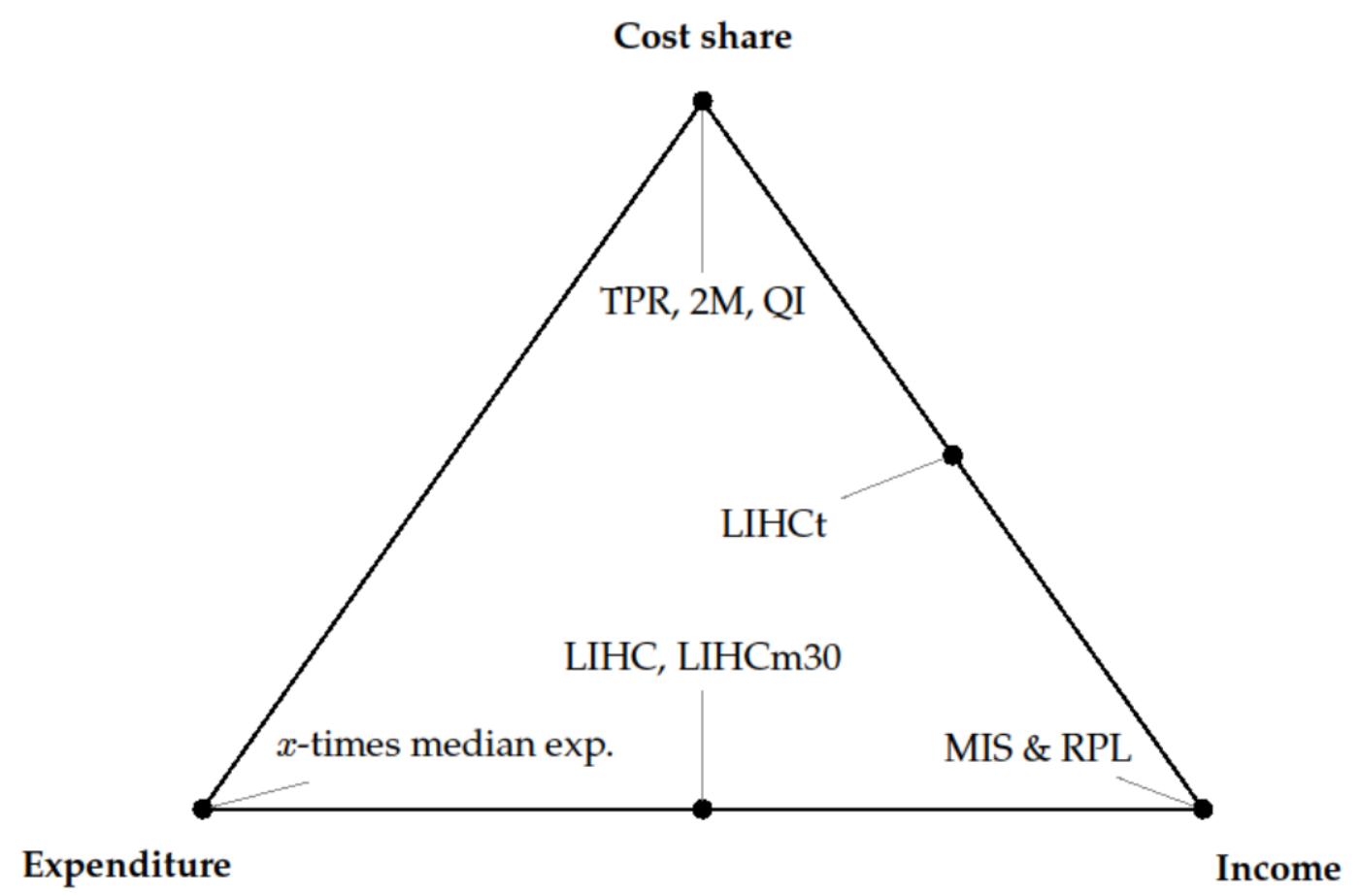

Figure 1: Overview of concepts used in definitions of affordability measures dependent on income, expenditure, or the share of expenditure relative to income. 
Affordability indicators for energy services can be characterized by their position in the indicator triangle. The prime example of the cost share approach is the TPR, according to which households that spend more than ten percent of their net income on adequate energy services are to be considered energy poor. Alternatively, the MIS indicator assumes that households are energy poor if their expenditure on adequate energy services pushes them below the official poverty line. A third indicator combines excessive expenditure and impoverishment, considering as energy poor any household that independently satisfies the two criteria of excessive expenditure for energy services and a cost push into poverty. This is the LIHC indicator's approach (other indicators, discussed below, can also be characterized by their position in the indicator triangle).

None of the indicators and interpretations of energy poverty broached so far preclude a transfer of standard requirements of poverty measurement to this field. Since the official poverty line or a modification of it figure in the MIS and LIHC indicators, the crucial three 'I' of poverty research seem applicable, providing three strands of information concerning the poor. $^{2}$ Poverty indicators should ideally record the incidence and intensity of poverty and reflect the extent of inequality among the poor. The same demand can prima facie be made with respect to quantitative measures of energy poverty. One problem seems to arise because the TPR does not postulate an income limit, but the three 'I' can also be linked to an expenditure share limit. There are good reasons for this, because each 'I' stands for a key concern of social policy. We need a head count of the poor, information about the depth of poverty and about the extent to which some people are worse off than others in order to design policies that prioritize support for those who are worse off. Priority for the worse off is a widely accepted demand in modern social ethics, and it is therefore reasonable for such policies to also be sought for energy poverty.

Does it follow that the axioms for poverty measures, which encapsulate the outlined requirements, should also apply to measures of energy poverty? A number of axioms for poverty measures have been postulated, but there is no consensus on a valid set of axioms. Zheng (1997) differentiates between core axioms and more peripheral or derivative ones. ${ }^{3}$ However, the extent to which Zheng's classification is accepted is unclear. Moreover, existing sets of axioms seem to not exhaust the relevant plausibility conditions for poverty

\footnotetext{
${ }^{2}$ See Esposito and Lambert (2011), and with different terminology (no I’s) Zheng (1997, p. 124).

${ }^{3}$ The notion of axiom currently (as is often the case in economics) refers to a condition indicators must satisfy rather than (as is the case in mathematics) to an independent foundational proposition, which cannot be derived from other foundational propositions.
} 
measurement. We will add some conditions here that may be in line with the spirit of certain axioms but are not covered by their formulation. In this somewhat unsettled situation, an axiom for an axiom discussion of energy poverty indicators does not seem advisable. We will therefore focus instead on specific indicators of energy poverty and their failure to meet particular plausibility conditions. As we will demonstrate for the well-known TPR, MIS, and LIHC indicators, such failures occur and the respective indicators (or their interpretations) need to be modified or abandoned.

TPR is closely associated with the research of Brenda Boardman. When Boardman (1991) conceived TPR based on 1988 data, the threshold simultaneously represented the average share of energy expenditure of the lowest 30 percent of incomes and double the median overall share of energy expenditure in the UK. These two characteristics need not coincide, and have in fact diverged since 1988. As an indicator of energy poverty, the TPR has normative import. Hence, the question arises which characteristic is better suited for normative interpretation. The standard claim is that the double median characteristic is that with normative import, because Isherwood and Hancock (1979) (purportedly) justified a double median threshold for excessive cost in the 1970s. Against this background, the British government seems to have made a mistake by establishing the TPR as an official indicator of energy poverty in 2001, because the double median share of household energy expenditure at the time no longer equaled ten percent. It follows that the TPR ought to be replaced by a double median share indicator. ${ }^{4}$

In point of fact, however, the British government may have been wise to not comply with this suggestion. The normative reasons for a double median share indicator of energy poverty are very tenuous, and this indicator thus seems arbitrary. It would, for instance, be just as good to refer to traditional criteria of just pricing in the debate on energy poverty and energy prices. The threshold for excess expenditure would then be 1.5 median share rather than double the median share. ${ }^{5}$ However, this discussion seems moot because neither the double median share threshold nor a limit derived from the theory of just pricing satisfies the basic plausibility requirement for poverty indicators, which we call:

Position Invariant Burdening (PIB): If the relative position of all persons in the distribution of income remains the same and all incomes are reduced by a positive amount, then the poverty measure $P$ should not decrease.

\footnotetext{
${ }^{4}$ For a more detailed discussion of the TPR and its interpretations, see Schüssler (2014).

${ }^{5}$ On just price in medieval economic thought, see Wood (2002, Chapter 6).
} 
The idea behind this approach is that a decrease in a society's real incomes should not be reflected in a concordant decrease of a poverty measure if the relative positions of all people remain constant. Otherwise, very poor societies might have smaller poverty rates than very rich societies with the same population and form of income distribution (i.e., same inequality). ${ }^{6}$ Standard relative poverty lines reflect this requirement. Reducing real incomes without adapting income distribution raises the poverty head count for the 60 percent median income poverty line. Surprisingly, however, none of the axioms of poverty measurement discussed by Zheng seems to require the observance of PIB. We nevertheless accept that requirement.

Under this premise, a simple statistical consideration reveals a deficiency of the double median share indicator for energy poverty (and all related double median indicators). Shifting a statistical distribution to the right by a positive constant c shifts the distribution's median $M$ for the same amount to $M+c$. This is also true for the shifted double median value $2 M+c$, but not for the new double median. The new double median is $2(M+c)$ and thus $c$ further to the right than the translated old median. Hence, less of the distribution's probability mass is in the tail beyond the new double median than was beyond the original double median. If the distribution in question is one of energy expenditure shares and the double median share is a threshold of energy poverty, it follows that fewer households (or people) are energy poor than before. Yet the addition of a constant reflects a position invariant increase in the energy expenditure for all households. For a uniform distribution of incomes, this amounts to a lumpsum increase in energy spending for all. For other distributions, the rise in expenditure will be positive for all but not equal in size. In any case, the double median share indicator suggests that a rise in energy expenditure for all, which does not affect the relative position of persons or the form of expenditure share distribution, will ceteris paribus lead to a reduction in energy poverty. This is obviously implausible. Rising real costs or shrinking real incomes for all should not result in lower recorded levels of poverty given that the relative positions of all persons remain the same.

It might be argued that this requirement follows from the notion of Amartya Sen's monotonicity axiom for poverty measures, which gives formal shape to the plausible

\footnotetext{
${ }^{6}$ Zheng (1997, p. 139) seems to be aware of this problem in his discussion of an axiom of scale invariance but does not pursue the issue and formulate a requirement.
} 
assumption that less money for the poor will increase poverty. The axiom of weak monotonicity in Zheng's version asserts: ${ }^{7}$

Weak Monotonicity: $P(x ; z)>P(y ; z)$ whenever $x \in D$ is obtained from $y \in D$ by a simple decrement to a poor person.

Here, $D$ is the set of income profiles below the poverty line $z$, while $x$ and $y$ are income profiles. The decrement reduces the income of one household or person in y and thus leads to $x$. In such cases, a poverty indicator should strictly increase. Unfortunately, the (here implicit) ceteris paribus clause of the axiom prevents a direct application of the monotonicity axiom to our case. If the expenditure shares of all other persons remain unchanged, an increase in the expenditure share of an energy poor person will raise energy poverty even for the double median share indicator. However, if the ceteris paribus clause only holds for income changes of poor people, ${ }^{8}$ the case is less clear-cut. This is not the place to pursue this interpretative problem, and we will therefore focus on PIB instead of on weak monotonicity.

As indicated, standard lines of relative poverty, such as a 60 percent median income poverty line, satisfy the requirements of PIB. For poverty lines of the form ' $q$ times median' it depends on the value of $q \in R^{+}$whether PIB is satisfied or not. For $q \leq 1$ the requirement is satisfied, but not for $q>1$. In light of this result, a double median share interpretation of the TPR (or any interpretation of $q>1$ ) should be avoided. However, it is compatible with PIB and other poverty axioms to retain the TPR as a fixed percentage threshold. Normative justifications for a fixed percentage threshold have to, of course, be sought. A suitable strategy would be a 'bottom up' justification of the TPR, analogous to the calibration of thresholds for absolute poverty. Hence, which kind of energy services a household absolutely needs and what share of income is required for these services could be assessed. TPR has the advantage of naming a simple round number and thus being easily communicable to the public. A detailed 'bottom up' construction of a fixed percentage threshold would only aid policy if the differences in measurement (at least the headcount and depth of energy poverty) were large enough to be significant.

Alternatively, the double median share criterion could be replaced by a different quantile-type indicator that satisfies PIB. A respective threshold should for the stated reasons not be conceived as a growing multiple of the median. Consequently, such an indicator is probably

\footnotetext{
${ }^{7}$ See Sen (1976). The axiom is presented in Zheng's formulation (1997, p. 131).

${ }^{8}$ The focus axiom, which asserts that a poverty measurement should be independent of the income distribution of the non-poor, seems to suggest this (Zheng, 1997, p. 130 ).
} 
best expressed as $r$-times (with $r<1$ ) a higher quartile or decile. Under this premise, Boardman's strategy of coupling the TPR with a quantile-type interpretation in a base year can be replicated. That is, it can, for instance, be calculated for which $r<1$ the value of $r$ times the 75 percent quartile expenditure share equals ten percent. Since the quantile is chosen to permit $r<1$, this threshold would satisfy the requirements of PIB. We will compare this new quantile indicator (QI) with the behavior of the double median share indicator.

Finally, all these expenditure share indicators should be truncated. A high share of energy expenditure for high incomes does not imply that the respective households become poor in any plausible sense of the term. Inasmuch, Isherwood and Hancock who initiated the interest in expenditure share indicators were right to talk about disproportionate energy costs, but not of energy (or fuel) poverty proper. ${ }^{9}$ Since we are interested in energy poverty, higher incomes for which high expenditure shares very likely fail to lead to poverty, should be excluded from consideration. Hence, we use Boardman's linkage of the TPR to the lowest three deciles of income for a truncation of the TPR and its suggested modifications. In other words, cognates of the TPR and quantile-type indicators are only calculated for the bottom three income deciles.

Another prominent indicator of energy poverty is the LIHC indicator proposed by Hills (2012, 2011). This indicator has replaced the TPR as the official English target value in the fight against energy poverty. LIHC has the advantage of more directly representing the idea of energy poverty as poverty caused by excessive expenditure for adequate energy services than the TPR. However, it is debatable whether the threshold for excessive expenditure should be the overall median of energy expenditure. Surely, as Hills argues, low income households appear overburdened if they have to spend more than the overall median on energy. Yet this does not justify setting the threshold at the median expenditure because households with less expenditure might already be overburdened. Moreover, the LIHC indicator is also incompatible with plausible demands of poverty measurement.

It should be possible for wealthy households to become poor by reducing their income (ignoring additional wealth for now). Nobody is so rich as to not become poor by being deprived of a sufficient amount of money. We call this the 'impoverishment axiom':

Impoverishment (IMP): For all particular incomes $x_{i}>z$ there is a decrement $d>0$ so that $x_{i}-d<z$ and $x_{i}-d \in x$. with $x \in D$.

\footnotetext{
${ }^{9}$ See Isherwood and Hancock (1979, part 1:3).
} 
It seems plausible that IMP also holds for energy poverty. There should be an amount of energy expenditure and income, or share of energy expenditure relative to income, at which any person or household becomes energy poor. Certainly, having to spend all income for adequate energy services will make a household (ceteris paribus) energy poor. Yet the LIHC indicator does not reflect this consideration. A household whose income shrinks so that expenditure for adequate energy services finally approaches total income will not be energy poor according to the LIHC indicator as long as its energy expenditure remains lower than the overall median. Hence, the LIHC indicator will fail to adequately represent energy poverty that is caused by an insufficient growth of real incomes (or even shrinking real incomes) relative to a significant growth of energy costs - hardly a merely academic possibility.

The LIHC indicator can be modified to avoid or mitigate this problem. One option we investigate is using an expenditure share threshold instead of an expenditure threshold as a first condition in the LIHC framework. Independently of this step, a lowering of the LIHC median threshold will be analyzed to gain a better understanding of the indicator's behavior under changing circumstances.

The last indicator to be discussed is MIS. MIS appears closest to a straightforward income poverty line approach to poverty. For this reason, MIS possesses none of the axiomatic shortcomings of TPR and LIHC. It does not follow, however, that MIS is therefore the only indicator deserving serious consideration. We have already signaled that modifications of the TPR and LIHC might help circumvent their conceptual shortcomings or interpretations. Moreover, MIS shares a disputable characteristic of LIHC: it is insensitive to changes in the income share of energy expenditure. Consider two households slightly below the poverty line. The income of the first is lower than the other's. Yet both have the same resulting position below the poverty line due to different amounts of adequate energy expenditure. It seems that the ex-ante richer household is relatively worse off and relatively poorer than the ex-ante poorer household, because it is less able to afford the ordinary lifestyle of its peers (its assumed reference group in terms of income). Hence, it may be in order to retain an expenditure share indicator such as the TPR to document shifts in expenditure shares, in particular for the lower income deciles for which it is not unreasonable to fear that adequate energy costs might push them into poverty. 


\subsection{Simulation of Dynamic Behavior: Data and Scenario Description}

\subsubsection{Data Description}

Data from the German Socio-Economic Panel (SOEP) are used to assess finite dynamic properties of several energy poverty measures. ${ }^{10}$ Data on disposable household income after taxes and benefits and expenditure on energy (space heating, water heating and electricity) at the household level are used for the simulation. Data are available for 8,507 households in Germany in 2010. Equivalized income (based on the 'new' OECD scale) is calculated to obtain a proxy for household income relative to household size (Kohn and Missong, 2003), which is needed to obtain some of the affordability measures. SOEP data were previously used to assess the incidence of income poverty (BMAS, 2013) and energy poverty in Germany (Heindl, 2013). Descriptive statistics are presented in Table 1.

Table 1: Descriptive Statistics of Data used for the Simulations

\begin{tabular}{lccccc} 
Variable & Mean & P25 & P50 & P75 & St. Dev. \\
\hline Household income & 2464 & 1400 & 2066 & 3084 & 1690 \\
Equiv. income & 1695 & 1100 & 1500 & 2000 & 1058 \\
Energy costs & 167 & 113 & 154 & 207 & 79 \\
Cost share rel. to income & 0.0873 & 0.0497 & 0.0733 & 0.1087 & 0.0571 \\
No. of persons in household & 2.02 & 1 & 2 & 3 & 1.14 \\
\hline $\begin{array}{l}\text { Overall number of available observations n=8,507, survey year 2010, data source: Socio-Economic Panel } \\
\text { (SOEP), data for years 1984-2012, version 29, SOEP, 2013, doi:10.5684/soep.v29. }\end{array}$
\end{tabular}

\subsubsection{Scenarios for Simulation and Considered Poverty Measures}

Four scenarios are considered in the simulation of dynamic properties of energy poverty measures:

A) Percentage increase in energy costs for each household: Expenditure on energy services is increased in steps of $10 \%, 20 \%, \ldots, 100 \%$ of initial energy expenditure for each individual household. This scenario simulates the case of increasing prices per unit of energy. This scenario is similar to a carbon tax levied on energy consumption.

B) Weighted increase in energy costs for each household: Cost increases are weighted in order to be neutral across the deciles of income distribution (i.e. non-regressive) in

\footnotetext{
${ }^{10}$ Socio-Economic Panel (SOEP), data for the years 1984-2012, version 29, SOEP, 2014, doi:10.5684/soep.v29. See Wagner et al. (2007) for a detailed description of the dataset.
} 
terms of incidence. Thus, increases in overall costs are lower for low-income vis-à-vis high income households. A 1 euro increase in costs in scenario A is equal to a 0.58 euro increase in costs for a household in the third decile of the income distribution in this scenario or a 1.32 euro increase for a household in the seventh decile of the income distribution. This scenario simulates the case of a carbon tax with neutral incidence.

C) Percentage decrease of income: Disposable household income is decreased in steps of $10 \%, 20 \%, \ldots, 100 \%$. This scenario is similar to the case of lost purchasing power or a general decrease of household income.

D) Percentage decrease of income (lowest 30 percent of incomes): Disposable household income of the lowest 30 percent of incomes is decreased in steps of $10 \%$, $20 \%, \ldots, 100 \%$, while the income of all remaining households and the expenditure on energy services remains unchanged. This scenario reflects the case of increased income inequality and increased income poverty.

Different measures of energy poverty are calculated for each scenario. This includes the ten percent rule (TPR), the two times median expenditure share indicator (2M), the low income/high cost measure (LIHC) and several variations of it, a minimum income standard approach (MIS), and the quantile indicator (QI). Table 2 summarizes the technical details of the applied measures.

\subsubsection{Evaluation Criteria}

Two criteria, as discussed in Section 2.2, are used to evaluate the simulation results. The first criterion is Position Invariant Burdening (PIB). It is related to Sen's monotonicity axiom (Sen, 1976). PIB requires energy poverty measures to increase monotonically as expenditure on energy services rises (all other things equal). As changes in energy prices often show systematic patterns, PIB is relevant for cases in which overall expenditure on energy services changes for all households (or a sufficiently large number of households). In practice, such situations could be oil price shocks or changes in energy prices due to taxation.

The second criterion is Impoverishment (IMP). If the income of all households were insufficient to cover the expenses of adequate energy services, it could be said that all households are subject to energy poverty. Thus, it is straightforward to expect energy poverty measures to increase as the population's income decreases, all other things equal. This proviso must hold for the case when income falls systematically (e.g. as a result of economic shocks 
causing increased income inequality) and when one household's income decreases. In other words, it must be possible to ‘impoverish’ a household by decreasing its disposable income.

Table 2: Details on used energy poverty measures

\section{Measure Method of calculation}

Ten percent measure (TPR) $\quad$ Energy poor if the share of expenditure on energy relative to income exceeds ten percent. In the simulation study, the TPR is restricted to the poorest 30 percent of households. Households in income brackets above 30 percent are excluded by definition.

\begin{tabular}{ll}
\hline $\begin{array}{l}\text { Two times median expenditure } \\
\text { share (2M) }\end{array}$ & $\begin{array}{l}\text { Energy poor if the expenditure share on energy exceeds two times } \\
\text { the median expenditure share in the overall population }\end{array}$ \\
\hline $\begin{array}{l}\text { Low income high cost standard } \\
\text { approach (LIHC) }\end{array}$ & $\begin{array}{l}\text { Energy poor if household has expenditure on energy above the } \\
\text { median and falls below the income poverty line after expenditure } \\
\text { on all energy services }\end{array}$ \\
\hline
\end{tabular}

LIHC with TPR as first Energy poor if households has an expenditure share equal to or condition (LIHCt) exceeding ten percent of income and falls below the income poverty line after expenditure on all energy services

LIHC with median expenditure $\quad$ Energy poor if household has expenditure on energy above median of poorest 30 percent of expenditure of the poorest $30 \%$ of incomes and falls below the households as first condition income poverty line after expenditure on all energy services (LIHCm)

Minimum income standard Energy poor if disposable income after expenditure on all energy (MIS) services is equal or less than the minimum income standard (MIS). German minimum income under basic social security (SGBIIrates) are used as MIS (see Heindl, 2013).

Quantile indicator (QI) $\quad$ Energy poor if the expenditure share exceeds ' $x$-times some upper quantile of energy expenditure' (with $x<1$ ) relative to income. For the simulation, the $9^{\text {th }}$ decile of energy expenditure relative to income was chosen and multiplied by the parameter 0.86 , so to be approximately equal to the value of TPR in the original situation.

Income Poverty (RPL) Energy poor if household falls below the (relative) income poverty line (RPL) after all expenditure on energy services. 


\section{Simulation Results}

\subsection{Results for Key Measures}

We first focus on the simulation results for the most prominent measures, either already being applied in practice or discussed in the literature, namely the ten percent rule (TPR), the two times median expenditure share indicator (2M), the 'standard' low-income high cost indicator (LIHC), and the minimum income standard (MIS). The simulation results are depicted in Figure 2.

\subsubsection{Position Invariant Burdening (PIB)}

For the case of a (regressive) percentage increase in energy expenditure (Scenario A), the TPR, LIHC, and MIS indicators are responsive and satisfy the requirements of PIB. In contrast, the 2M remains unchanged as energy expenditure is increased for all households.

The case of a non-regressive (weighted) increase of the households' energy expenditure (Scenario B) is of particular interest. In this scenario, increases in energy expenditure are weighted so that they satisfy the principle of equal (monetary) sacrifices. The share of expenditure on all energy services relative to income is equal for all deciles of the income distribution in this scenario. This simulates the case of a progressive carbon tax. In this scenario, the TPR and MIS respond to the absolute increase in energy expenditure (given constant relative burdens across the income distribution) and satisfy PIB. In contrast, the 2M and LIHC decrease, even though expenditure for energy services increases for all households in absolute terms. The reason for this counter-intuitive result is that an adjustment of burdens changes the distribution of energy costs across households (with wealthier households carrying larger absolute burdens), while the relative position of all households in the distribution remains unchanged. As both measures define energy poverty based on the median of the expenditure distribution, the measures are unable to capture the dynamics of energy poverty if there is redistribution in favor of the poor, but not as much as to alter their relative positions on the income scale.

\subsubsection{Impoverishment (IMP)}

IMP requires that it must be possible to push a household into energy poverty by decreasing its disposable income. For the case of stepwise percentage decreases of all incomes across the income distribution (Scenario C), the TPR, the LIHC, and the MIS increase to their maximum levels. The 2M remains unchanged when all incomes are decreased. IMP is impossible given 
the $2 \mathrm{M}$ definition because the overall distribution of energy expenditure remains unchanged in this scenario. Therefore, the indicator does not change until it collapses, when all incomes approach the assumed minimum of 1 euro. ${ }^{11}$

A case of particular interest is when income inequality is increased (Scenario D). This is modelled by successively decreasing the incomes in the lowest three income brackets while leaving the overall expenditure on energy services unchanged. The TPR, the $2 \mathrm{M}$, and the MIS respond to the increase in income inequality and the corresponding increase in relative burdens of the cost for energy services. In contrast, the LIHC shows a weak response to the increase in income inequality. The LIHC slightly increases when the income of the poor decreases up to 30 percent, but the indicator remains unchanged when incomes are further decreased. Therefore, the LIHC does not satisfy the proviso of IMP. The LIHC's weak response is attributable to the first condition of the measure stating that energy poverty depends on the median of energy expenditure in the overall population. Because a household will never qualify as energy poor if its expenditure on energy services does not exceed the median expenditure, 50 percent of households will not satisfy IMP. This is of particular relevance for low-income households in which the average energy expenditure is lower in comparison with wealthier households because of positive income elasticities of energy demand (Karimu and Brännlund, 2013; Narayan et al., 2007) and possible pre-existing deprivation.

\subsection{Results for Alternative Indicators}

Overall, the TPR and MIS satisfy PIB and IMP in all of the considered scenarios. The 2M and LIHC violate both propositions in some of the scenarios. Modified versions of the LIHC and the $2 \mathrm{M}$ are tested for compatibility with PIB and IMP. An alternative to the (fixed) income poverty line of the MIS will also be considered. The simulation results for alternative measures are depicted in Figure 3.

\subsubsection{Alternatives to LIHC}

Alternatives to the LIHC pivot around a modified first condition of the measure, i.e. the condition of 'expenditure above median'. As an alternative, the first condition could be defined as requiring a household to spend at least $x$ percent of its disposable income on all energy services. It is straightforward to include the TPR (or any other expenditure share) as a

\footnotetext{
${ }^{11}$ The least income was chosen to equal 1 euro to avoid issues of division by zero.
} 
first condition here (LIHCt). The LIHCt definition is compatible with PIB and IMP in all of the considered scenarios. However, as the LIHCt is stricter than the TPR alone, the overall figures on energy poverty are lower for the LIHCt than for TPR alone, except in the case of decreased incomes where the LIHCt and TPR approach their maximum of 30 percent (as required by IMP).

Instead of using the median expenditure of the overall sample, the median expenditure of the lower three income brackets could be used as a first condition (LIHCm30) to give priority to the economic situation of the poor. The rationale for this choice is that low-income households are particularly vulnerable to increased prices of necessities. The LIHCm30 definition is compatible with PIB and IMP in all scenarios with the exception of increased inequality of the poor (Scenario D), where it violates both propositions.

\subsubsection{Alternatives to $2 \mathrm{M}$}

As an alternative to $2 \mathrm{M}$, the definition of ' $x$-times some upper quantile of energy expenditure' (with $x<1$ ) relative to income was discussed in Section $2.2(\mathrm{QI})$. For the simulation, the $9^{\text {th }}$ decile of energy expenditure relative to income was chosen and multiplied by the parameter 0.86 , so as to be approximately equal to the value of the TPR in the original situation. Both the parameter and the $9^{\text {th }}$ decile are chosen arbitrarily, as the sole purpose is to test the dynamic properties of such a measure. The simulation results show that such a QI measure would have similar deficiencies as the $2 \mathrm{M}$ definition from a dynamic perspective. The indicator violates the PIB and IMP in several situations.

\subsubsection{Alternatives to MIS}

The MIS definition as used in this paper relies on a household-specific absolute income poverty line. The income poverty line is chosen to represent allowances under the basic social security scheme in Germany (SGBII rates). The absolute income poverty line is treated as exogenous in the simulation. A potential alternative to the MIS definition would be to use a definition of relative income poverty, such as the widely accepted poverty line of 60 percent median income (RPL). The RPL was applied so that it is endogenous and based on equivalized household income. A household is defined as energy poor if its disposable income falls below the relative income poverty line of 60 percent median income after all expenses for energy services. The simulation results show that RPL is compatible with PIB and IMP in all but one of the considered scenarios. In the case of increased income inequality, i.e. when the income of the lower three income brackets decreases, the RPL remains constant when 
incomes decrease by more than 40 percent. At first glance, this appears to be a violation of the PIB. However, the result hinges on the relative income poverty line. The relative income poverty line remains unchanged, as it ought to once the incomes of the lower three income brackets approach the minimum value in the simulation. Therefore, a violation of PIB is appropriate in the scenario setup in this specific situation.

\section{Discussion}

In general, the TPR, MIS, LIHCt, and RPL satisfy PIB and IMP, whereas the LIHC and 2M violate one or both conditions in some scenarios (Table 3). What drives this result? $2 \mathrm{M}$ and LIHC are defined based on location parameters (the median or values greater than the median). 2M and LIHC appear to be sensitive to changes in the moments of the underlying distributions. The simulation results support this view.

A household's energy expenditure needs to lie above the median and fall below the relative income poverty line after all expenditure on energy services to qualify as energy poor according to the LIHC. The LIHC is incapable of capturing the incidence of increased expenditure in the presence of an ex-post adjustment of energy expenditure (Scenario B) and fails to mirror the consequences of increasing inequality in incomes (Scenario D). The first aspect is of high relevance with respect to energy and climate policy. If prices for energy services increase as consequence of policies for the protection of the climate, and if measures are taken to redistribute the burdens of climate policy according to the principle of 'equal sacrifice', the LIHC will potentially decrease (i.e. indicating an increase in affordability of energy services), even though the total cost of energy services increases for all households, all other things equal. Redistribution partly offsets energy price increases. Thus, redistribution works against the conditions of the LIHC, even if there is an absolute decrease in affordability (or an increase in expenditure share). It is important to note that this result is valid for cases in which the expenditure distribution is changed so that increased costs are distributed in a 'neutral' or 'position invariant' way. This is different from the case of an ex-post redistribution of income.

The LIHC is further unable to capture increased inequality in household incomes: if the incomes of households in the lower three deciles of the income distribution are successively reduced to eventually equal 1 euro per month, the LIHC increases marginally. Rising inequality is independent of the condition 'expenditure above median', which causes the moderate response of the LIHC to increased inequality. 
Similar problems occur for the 2M definition: a household is defined as energy poor if its expenditure share on energy services exceeds two times the median expenditure share of the overall population. The $2 \mathrm{M}$ measure fails to capture systematic increases in expenditure, because $2 \mathrm{M}$ becomes increasingly restrictive as the overall population's expenditure on energy services increases. This causes the decrease of the $2 \mathrm{M}$ measure in Scenario B. $2 \mathrm{M}$ is further unable to capture a systematic increase of expenditure or a systematic decrease of incomes, as this causes a likewise systematic change in the expenditure shares and thus leaves the $2 \mathrm{M}$ condition unchanged in Scenario A and Scenario C. ${ }^{12}$

These results are of relevance for alternative definitions of affordability measures. The LIHC can be modified to include the TPR as a first condition (LIHCt) instead of the condition ‘expenditure above median'. The LIHCt satisfies the PIB and IMP. As depicted in Figure 3, the LIHCt is responsive to regressive and non-regressive increases in expenditure, to decreasing incomes, and to an increase in inequality. This observation supports the view that the condition 'expenditure above median' in the original version of the LIHC causes unintuitive dynamic behavior in Scenarios B and D.

It is important to note that the results of this paper focus exclusively on fundamental dynamic properties of affordability measures but have no direct implications for the 'static' definition of affordability measures. As depicted in Figures 2 and 3, the response of the different measures to changes in the underlying variables differs. Some measures (e.g. the TPR) show quite pronounced responses while others (e.g. the MIS) only show moderate reaction. It is an empirical question how strongly an affordability measure needs to respond to changes in underlying variables in order to capture the changes in affordability or deprivation. This question, which is left for future research, needs to be answered for specific cases or types of goods and be based on empirical evidence.

\section{Conclusions and Policy Implications}

This paper investigates the dynamic behavior of energy affordability measures. Measures of affordability are used in practice or are proposed as policy instruments to assess the affordability of goods such as energy services, water, and housing. Affordability measures, by definition, are based on income and expenditure for specific goods, and thus define a poverty line based on multiple criteria and 'tacit weighting' (Alkire and Foster, 2011). While well-

\footnotetext{
${ }^{12}$ In some cases, the $2 \mathrm{M}$ even decreased, e.g. in the case of a lump-sum increase in energy expenditure across income distribution.
} 
established axioms on the dynamics of aggregated poverty measures based on a single criterion exist, no such criteria are available for affordability measures. Measures of affordability comprise normative statements about how non-affordability is defined, as is the case for virtually all definitions of deprivation. With respect to these normative statements, two domains can be distinguished. Firstly, how affordability is defined at one point in time, and secondly, how affordability changes over time as a result of changes in underlying key variables. The latter aspect, i.e. the 'dynamics' of affordability measures, has so far received virtually no attention in the literature.

Two propositions are made about how affordability measures should respond to changes in underlying key variables: Position Invariant Burdening (PIB) is motivated by a standard axiom in poverty measurement, namely monotonicity (Sen, 1976). PIB requires that a measure of non-affordability increases if the actual expenditure on the respective goods increases in society without a change in individual positions. Impoverishment (IMP) requires that it must be possible to push a household below the poverty line by decreasing the household's income below a certain threshold.

Based on a microsimulation approach, dynamic behavior of a number of affordability measures is examined. This includes the 'ten percent rule' (TPR), the 'low income/high cost measure' (LIHC), and the 'two times median expenditure share' (2M), which have been applied to assess fuel poverty in the UK (Department of Energy and Climate Change, 2013; Hills, 2012; Liddell et al., 2012; Moore, 2012). Alternative definitions rely on an absolute poverty line in the sense of a 'minimum income standard' (MIS) (Bradshaw et al., 2008; Saunders, 2004, 1999) or on a relative income poverty line (PRL). Modifications of the LIHC measure (LIHCt, LIHCm30) and the 2M measure (QI) are examined as well.

In general, the TPR, MIS, RPL, and LIHCt satisfy the PIB and IMP, while 2M, LIHC, LIHCm and QI do not satisfy the PIB and IMP. 2M is fully unable to capture an increase in economy-wide energy expenditure or a decrease of incomes. The LIHC fails to capture an increase in economy-wide energy expenditure with ex-post redistribution (neutral distribution of relative burdens across income brackets). Even though energy expenditure and relative burdens increase in all income brackets in this scenario, the LIHC does not indicate a decrease in energy affordability. This property of the LIHC is particularly problematic, as redistribution takes place in most advanced economies and the LIHC fails to provide robust information about (dynamic) energy affordability in this situation. The LIHC is further unable to capture the consequences of increased income inequality on energy affordability. In the 
case of increased income inequality, the LIHC is non-responsive, even though energy affordability for poorer households decreases dramatically in this scenario. Alternative measures such as QI or LIHCm exhibit similar flaws. The TPR, the MIS, and the RPL have desirable properties from a dynamic perspective. The LIHCt seems to be a good combination of the TPR and MIS. It is also the only acceptable indicator in our test that reflects two different considerations of affordability (i.e., it is the only remaining indicator on a side of the indicator triangle). All remaining indicators are responsive to changes in energy expenditure and income of households in all scenarios. The results have important implications in practice: measures following the logic of the $2 \mathrm{M}$ or LIHC definition potentially exhibit dynamic inconsistencies while measures following the logic of the TPR, MIS, RPL, or LIHCt appear more appropriate from a dynamic perspective.

\section{References:}

Alkire, S., Foster, J., 2011. Counting and multidimensional poverty measurement. Journal of Public Economics 95, 476-487.

Blackorby, C., Donaldson, D., 1980. Ethical indices for the measurement of poverty. Econometrica 48, 10531060.

BMAS, 2013. Lebenslagen in Deutschland. Bundesministerium für Arbeit und Soziales, Berlin.

Boardman, B., 1991. Fuel Poverty: From Cold Homes to Affordable Warmth. Belhaven Press, London.

Boardman, B., 2012. Fuel poverty synthesis: Lessons learnt, actions needed. Energy Policy 49, $143-148$.

Bourassa, S., 1996. Measuring the Affordability of Home-ownership. Urban Studies 33, 1867-1877.

Bradshaw, J., Middleton, S., Davis, A., Oldfield, N., Smith, N., Cusworth, L., Williams, J., 2008. A Minimum Income Standard for Britain. Leicestershire, UK.

Department of Energy and Climate Change, 2013. Fuel Poverty Report - Updated August 2013. London.

Esposito, L., Lambert, P., 2011. Poverty Measurement: Prioritarianism, Sufficiency, and the "I”s of Poverty. Economics and Philosophy 27, 109-121.

Foster, J., Greer, J., Thorbecke, E., 1984. A Class of Decomposable Poverty Measures. Econometrica 52, 761766.

García-Valiñas, M.A., Martínez-Espiñeira, R., González-Gómez, F., 2010. Affordability of residential water tariffs: alternative measurement and explanatory factors in southern Spain. Journal of environmental management 91, 2696-706.

Gawel, E., Sigel, K., Bretschneider, W., 2013. Affordability of water supply in Mongolia: empirical lessons for measuring affordability. Water Policy 15, 19. 
Halleröd, B., 2006. Sour Grapes: Relative Deprivation, Adaptive Preferences and the Measurement of Poverty. Journal of Social Policy 35, 371-390.

Hancock, K.E., 1993. “Can Pay? Won”t Pay?’ or Economic Principles of “Affordability.” Urban Studies 30, 127-145.

Healy, J.D., 2004. Housing, Fuel Poverty and Health: A Pan-European Analysis. Ashgate Publishing, Aldershot.

Heindl, P., 2013. Measuring Fuel Poverty: General Considerations and Application to German Household Data. ZEW Discussion Paper Nr. 13-046.

Hills, J., 2011. Fuel Poverty: The problem and its measurement - Interim Report of the Fuel Poverty Review. London.

Hills, J., 2012. Getting the Measure of Fuel Poverty: Final Report of the Fuel Poverty Review. London.

Isherwood, B.C., Hancock, R.M., 1979. Household Expenditure on Fuel: Distributional Aspects. London, UK.

Kakwani, N., 1980. On a Class of Poverty Measures. Econometrica 48, 437-446.

Karimu, A., Brännlund, R., 2013. Functional form and aggregate energy demand elasticities: A nonparametric panel approach for 17 OECD countries. Energy Economics 36, 19-27.

Kohn, K., Missong, M., 2003. Estimation of Quadratic Expenditure Systems Using German Household Budget Data. Jahrbücher für Nationalökonomie und Statistik 223, 421-448.

Liddell, C., Morris, C., McKenzie, S.J.P., Rae, G., 2012. Measuring and monitoring fuel poverty in the UK: National and regional perspectives. Energy Policy 49, 27-32.

Moore, R., 2012. Definitions of fuel poverty: Implications for policy. Energy Policy 49, 19-26.

Narayan, P.K., Smyth, R., Prasad, A., 2007. Electricity consumption in G7 countries: A panel cointegration analysis of residential demand elasticities. Energy Policy 35, 4485-4494.

OECD, 2011. Divided We Stand: When Inequality Keeps Rising. OECD Publishing, Paris.

Papadopoulos, F., Tsakloglou, P., 2008. Social exclusion in the EU. A capability-based approach, in: Comim, F., Qizilbash, M., Alkire, S. (Eds.), The Capability Approach, Concepts, Measures, and Applications. Cambridge University Press, Cambridge, pp. 242-257.

Pogge, T., 2007. Freedom from Poverty as a Human Right: Who Owes What to the Very Poor. Oxford University Press, Oxford.

Saunders, P., 1999. Budget Standards and the Poverty Line. The Australian Economic Review 32, $43-61$.

Saunders, P., 2004. Updated budget standard estimates for Australian working families in September 2003. Sydney.

Schüßler, R., 2014. Energy Poverty Indicators: Conceptual Issues - Part I: The Ten-Percent-Rule and Double Median/Mean Indicators. Centre for European Economic Research (ZEW) Discussion Paper 14-037.

Sen, A., 1976. Poverty: An Ordinal Approach to Measurement. Econometrica 44, 219-231.

Snell, C., Thomson, H., 2013. Reconciling fuel poverty and climate change policy under the Coalition government: Green Deal or no deal?, in: Ramia, G., Farnsworth, K., Irving, Z. (Eds.), Social Policy Review 25. Policy Press, Bristol, pp. 23-45. 
Wagner, G.G., Frick, Joachim, R., Schupp, J., 2007. The German Socio-Economic Panel Study (SOEP) - Scope, Evolution and Enhancements. Schmollers Jahrbuch 127, 139-169.

Wood, D., 2002. Medieval Economic Thought. Cambridge University Press, Cambridge.

Zheng, B., 1997. Aggregate Poverty Measures. Journal of Economic Surveys 11, 123-162. 


\section{A: Percentage Cost Increase}

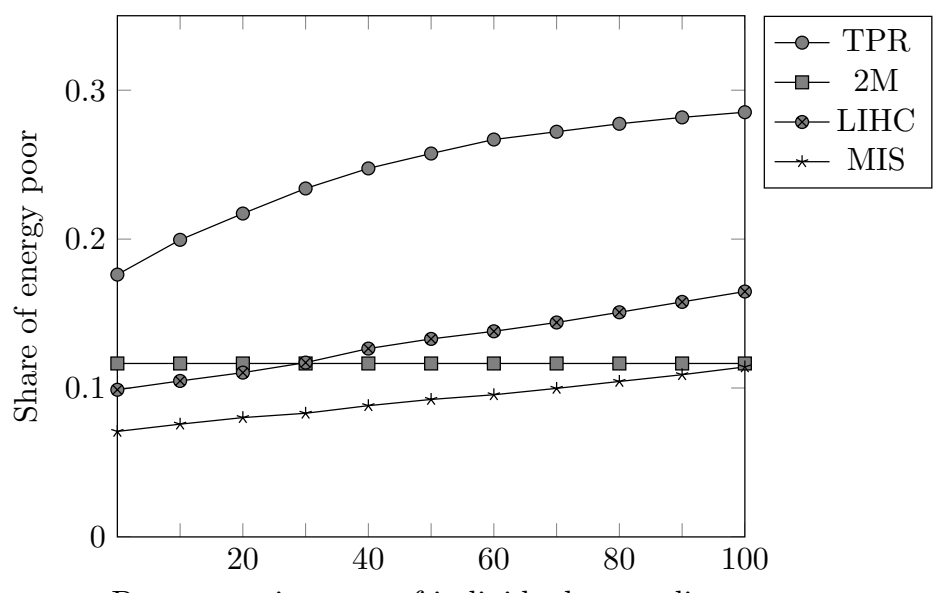

Percentage increase of individual expenditure

\section{C: Decrease of Income}

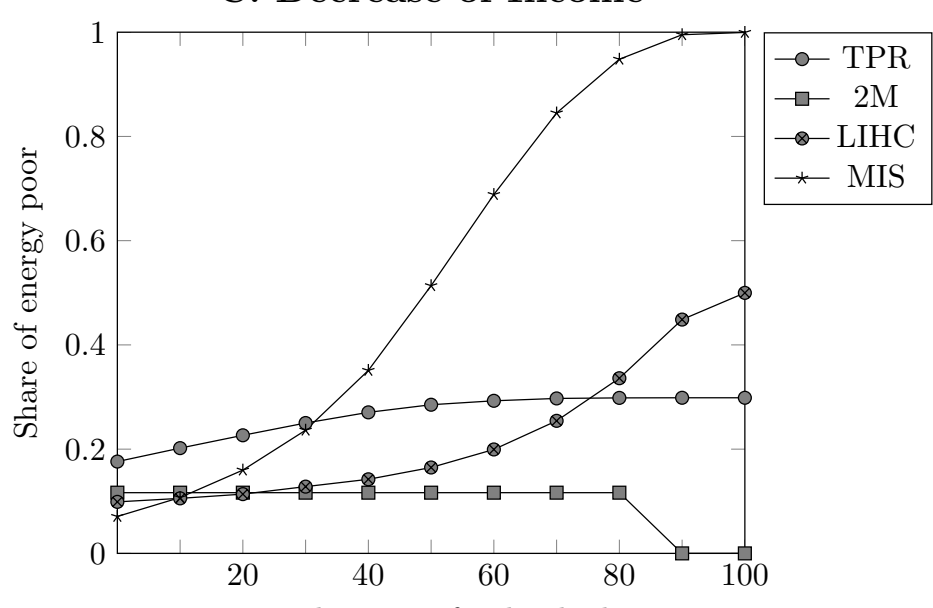

Percentage decrease of individual income
B: Non-Regressive Cost Increase

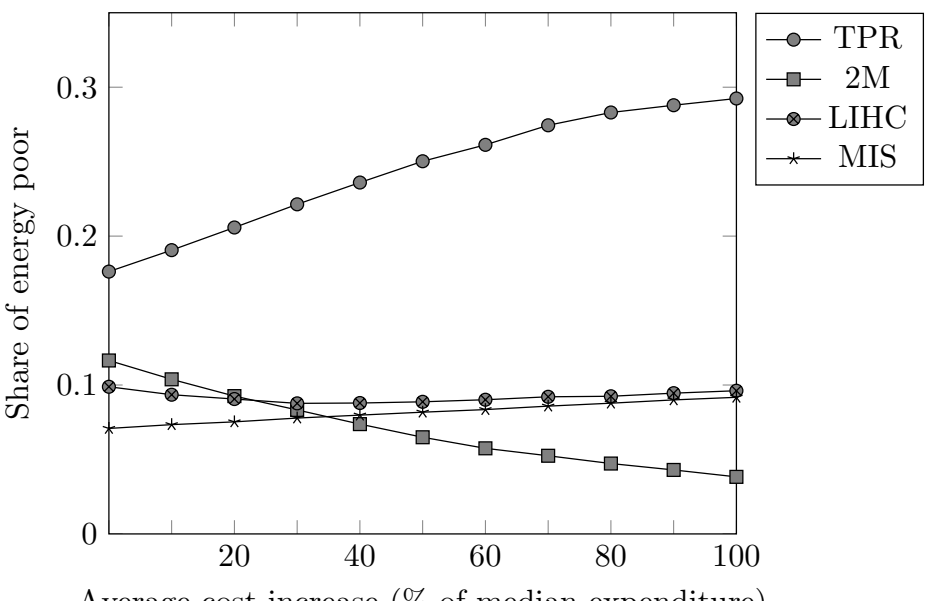

Average cost increase (\% of median expenditure)

D: Decrease of Income (only lower $30 \%$ )

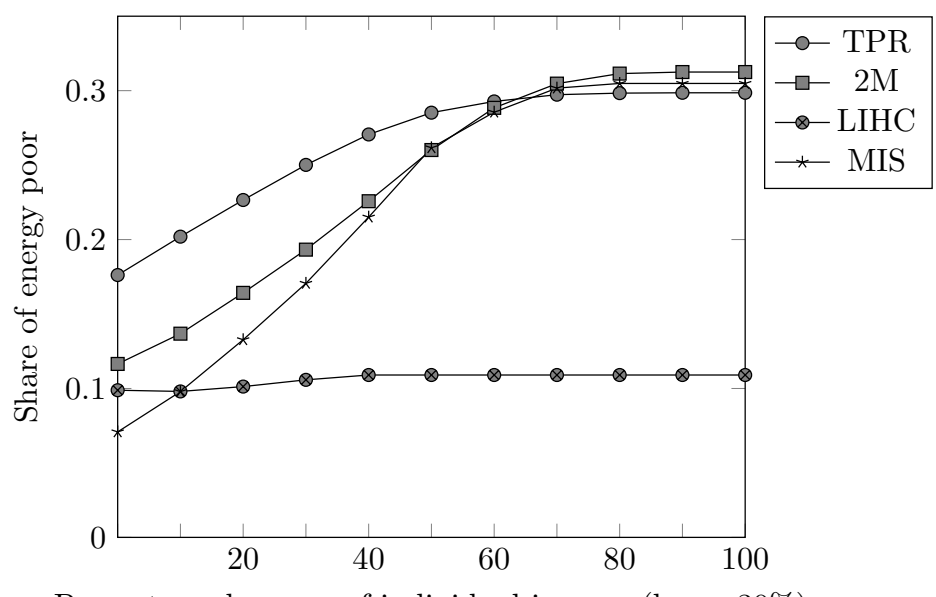

Percentage decrease of individual income (lower 30\%)

Figure 2: Dynamic behavior of energy affordability measures under Scenarios A to D. 
A: Percentage Cost Increase

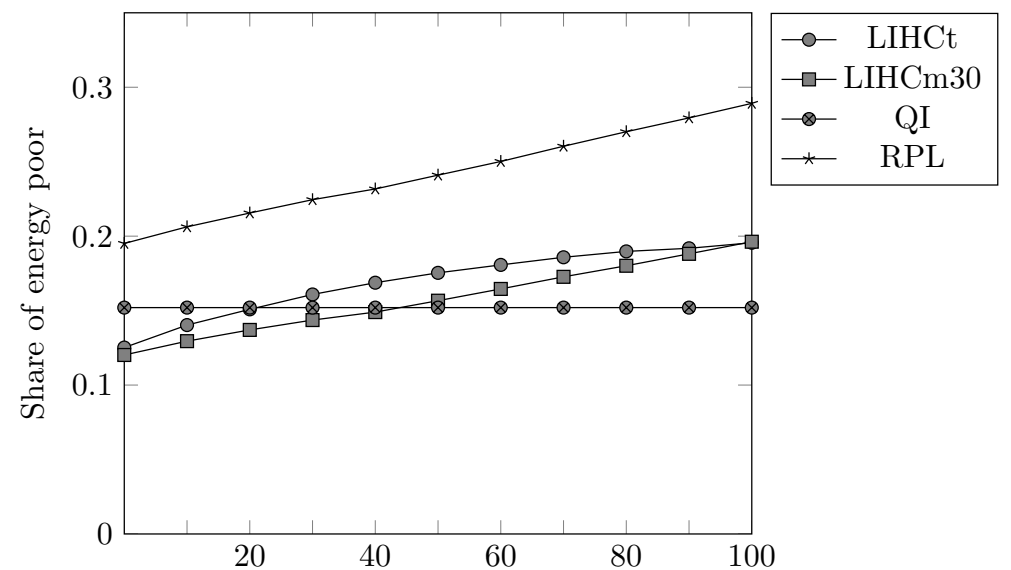

Percentage increase of individual expenditure

\section{C: Decrease of Income}

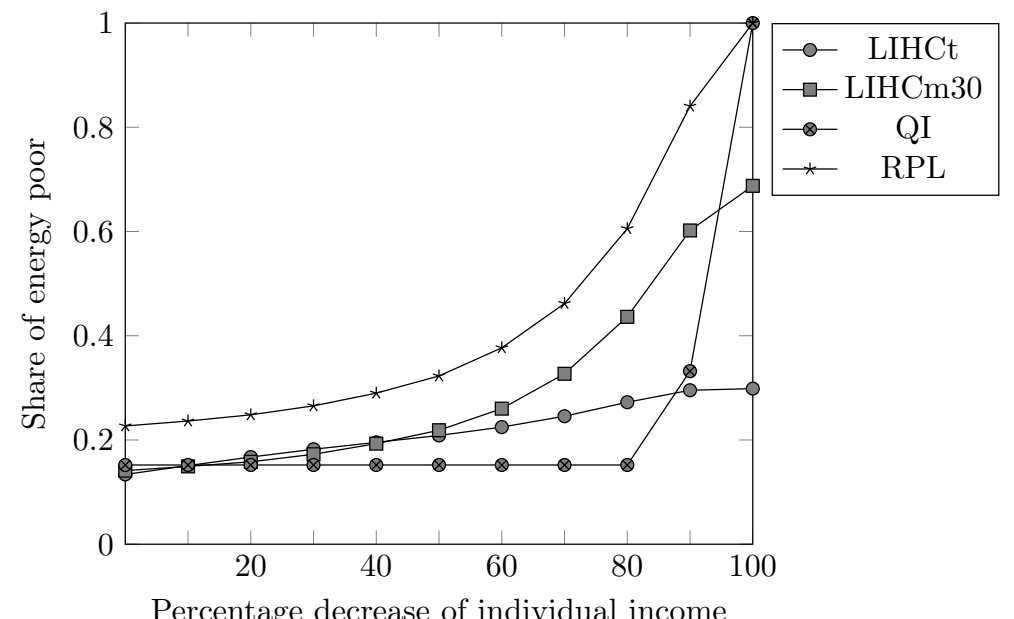

B: Non-Regressive Cost Increase

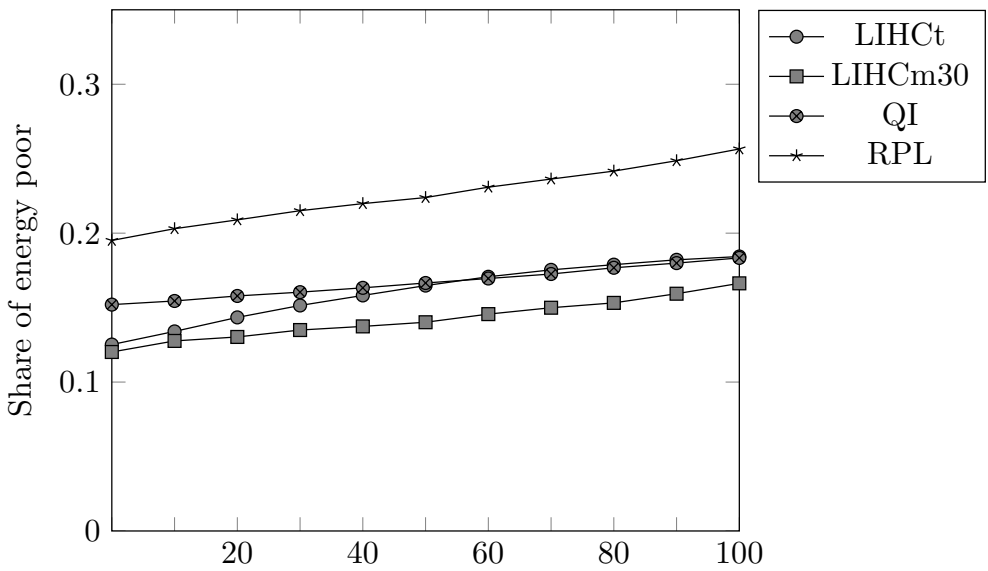

Average cost increase ( $\%$ of median expenditure)

D: Decrease of Income (only lower $30 \%$ )

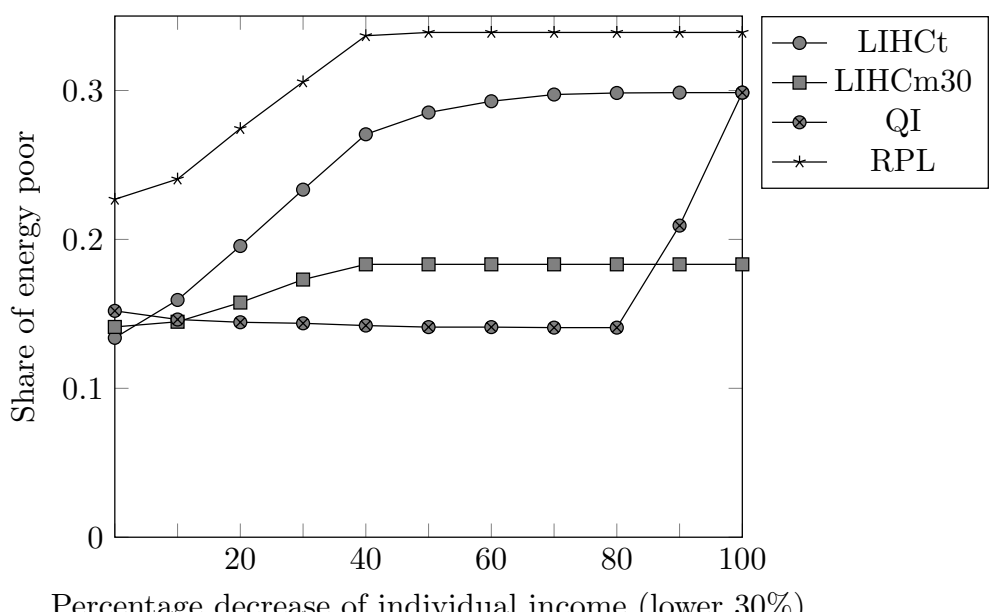

Figure 3: Dynamic behavior of alternative energy affordability measures under Scenarios A to D. 
Table 3: Summary of dynamic properties of energy poverty measures

\begin{tabular}{|l|l|l|l|l|l|l|l|}
\hline & TPR & 2M & LIHC & LIHCt & LIHCm30 & MIS & RPL \\
\hline
\end{tabular}

